\title{
Exploring Student Experiences in Early Computing Courses during Emergency Remote Teaching
}

\author{
McKenna Lewis, Zhanchong Deng, Sophia Krause-Levy, Adrian Salguero, William G. Griswold, \\ Leo Porter, Christine Alvarado \\ University of California, San Diego \\ \{m2lewis,zhdeng,skrausel,asalguer,wgg,leporter,cjalvarado\}@eng.ucsd.edu
}

\begin{abstract}
Spring 2020 brought enormous change to student learning, as universities scrambled to put into place support structures to aid students' learning in a remote context. Computer science education was both well-positioned for this change and faced unique challenges, e.g. that students often need significant (in-person) support with programming. In this study we examine how aspects of students' remote learning experience in spring 2020 compared to the same aspects in previous in-person, pre-COVID offerings of 6 lowerto mid-division computer science courses at UC San Diego (UCSD), a large US research university. We were in a unique position to make this comparison because we had been collecting data on several aspects of students' course experiences throughout the 2019-2020 academic year. We found, surprisingly, that most elements of students' experiences that we examined were unchanged, or even improved, in spring 2020. Students in spring reported similar or lower stress levels and found their courses similarly or less challenging relative to previous quarters. However, some aspects did degrade. Students had less connection with their peers (particularly in introductory classes), more interference from family obligations, and higher drop/fail rates in some classes. Surprisingly, these results hold across all assessed demographics. Our results indicate that the actions UCSD and its CS instructors took to mitigate the stresses of remote learning in spring 2020 were largely successful and provide implications for improving education beyond the pandemic.
\end{abstract}

\section{CCS CONCEPTS}

- Social and professional topics $\rightarrow$ Computing education.

\section{KEYWORDS}

remote education; undergraduate CS; student stress; COVID-19

\section{ACM Reference Format:}

McKenna Lewis, Zhanchong Deng, Sophia Krause-Levy, Adrian Salguero, William G. Griswold, Leo Porter, Christine Alvarado. 2021. Exploring Student Experiences in Early Computing Courses during Emergency Remote Teaching. In 26th ACM Conference on Innovation and Technology in Computer Science Education V. 1 (ITiCSE 2021), fune 26-fuly 1, 2021, Virtual Event, Germany. ACM, New York, NY, USA, 7 pages. https://doi.org/10.1145/3430665. 3456315

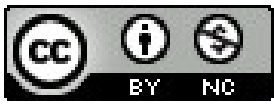

This work is licensed under a Creative Commons Attribution-NonCommercial International 4.0 License.

ITiCSE 2021, fune 26-fuly 1, 2021, Virtual Event, Germany.

(C) 2021 Copyright held by the owner/author(s).

ACM ISBN 978-1-4503-8214-4/21/06.

https://doi.org/10.1145/3430665.3456315

\section{INTRODUCTION}

In spring 2020, the majority of universities in the United States, like those in much of the world, were forced to switch quickly to remote learning. Each institution, its faculty, and its students alike scrambled to adapt to this new educational reality, with little prior experience to build on. Institutions hastily set new policies, faculty improvised in their course designs, and students invented new habits to accommodate study settings that weren't necessarily of their choosing. One might expect that such a large and complex sociotechnical system would adapt poorly-at least in the short term-negatively impacting the student experience.

In early programming classes, instructional teams and students had specific advantages and faced differing challenges compared to those in other disciplines. On the one hand, since much of their work is done on computers, little about their weekly process necessarily had to change. On the other hand, students in these courses receive much of their support in an in-person lab setting, which also had to go remote, and students were forced to use their own computing equipment instead of using the university's pre-configured machines. Additionally, students were no longer able to engage in practices such as in-person pair programming.

This paper contributes a data-driven, exploratory analysis of the spring 2020 computer science (CS) student experience at UC San Diego (UCSD), compared to the preceding fall and winter quarters. We were in a unique position to perform this study. As part of a larger effort to understand students' experiences in our early programming courses, we had been collecting weekly or bi-weekly survey data from students in six lower- and mid-division programming courses in fall 2019 and winter 2020, and we continued these surveys into the spring quarter. These surveys asked students a variety of questions about their experience and attitudes inside and outside the course. We specifically examined the following factors: overall stress, perceived course challenge, connections to peers, external factors interfering with learning, and weekly hours spent on the course. We also examined the rate at which students dropped and failed courses in spring 2020 compared to previous quarters.

We found that, when comparing the student experience in the emergency remote setting to the experience in a typical quarter:

- Surprisingly, students' overall course experience, as measured by the above factors, was quite similar. On average, students experienced similar (or lower) levels of stress, perceived the courses to be similarly challenging, and spent approximately the same number of hours on the course. Likewise, drop and failure rates were not notably higher than historical norms.

- Moreover, disaggregating by gender, race/ethnicity, and transfer status suggests that the shift did not increase disparities. 
- However, students expressed connection and comfort with fewer peers in spring in nearly all courses we studied, but particularly in the early introductory courses.

We conclude, then, that the complex sociotechnical system that delivers university education was nimble enough to create a comparable educational experience for our students, and we believe many of the adaptations, if continued, will lead to an improved experience in normal times. The one critical exception is that the system was not able to sufficiently provide mechanisms to combat the isolation students felt from their peers. Institutions, faculty, and students would be advised to pay special attention to fostering educational learning communities in future emergencies.

\section{PREVIOUS WORK}

\subsection{Emergency Online Teaching}

Studies are emerging examining how students and faculty perceived and adjusted to remote learning in spring 2020. Examining the students' perspective, an early survey-based study found that students' overall anxiety level was inversely correlated with how positively they viewed remote learning, and that they were worried about several things including their grades, their learning, and social connections to their peers [14]. Dingwall reported on a successful emergency remote course structure in a large biochemistry course and found that while many aspects of the course translated well to the online format, some aspects such as closed-book, proctored exams did not. [8]. In computing, Mooney and Becker found that the pandemic lowered students' sense of belonging on average, but that this trend was strongest for men who do not identify as belonging to any minority group [17]. Thiry and Hug investigated the impact of the pandemic at Hispanic Serving Institutions and found that these institutions had taken creative and varied approaches that were often successful in supporting students' additional hardships caused by the pandemic [21].

On the faculty side, a team from the Computing Research Association surveyed 450 computing faculty members at universities and colleges around the world. They found that while faculty felt that some aspects of their online courses were better than in the in-person version, only $37 \%$ agreed that students learned about the same amount in the online format as they would have in person [4]. Another study conducted in the UK found that CS professionals felt more confident and prepared than their non-computer science peers with the rapid online switch [6]. Computer scientists also were significantly more likely to agree that their students would be able to access the online learning platforms and material.

Our work complements the above work by providing a broader view of the CS student experience in spring 2020 compared to previous terms. We combine student survey, grade, and enrollment data from multiple courses and compare it to data collected before the pandemic that is not skewed by their reaction to the pandemic.

\section{$2.2 \quad$ Remote Teaching}

More generally, distance learning is not new. Studies consistently find that students, especially older-adult students, perceive many advantages of distance learning, including increased flexibility and self-guided study $[10,12,15]$. Some studies show that online learning can be an adequate alternative to face-to-face learning. Paul and Jefferson found no difference in student learning over a long period (2009-2016) between face-to-face and online learners in an undergraduate environmental science course [18]. In a recent CS study, Bahamón and Rorrer compared outcomes between an online and in-person format of an introductory programming course, finding that achievement was similar [2].

Yet many studies also find that distance learning has drawbacks, especially for CS courses. In an early study, McDonald et al. found that students in an upper-division database systems course performed worse in an online offering compared to an in-person version [16]. Fojtík found that students in a CS program found distance learning to be more challenging than expected and had lower success rates than in-person students, particularly in early classes [11]. In a comparison of online and flipped versions of a programming course, Campbell et al. found that while students' experiences were similar in terms of time spent on the course, students in the online section did significantly fewer out-of-class exercises, which was correlated with lower performance [5].

Benda et al.'s interview study with adult CS distance learners found that the process of learning to program was unpredictable, making it difficult for students to plan their time, and that the online communication modalities were inadequate for getting the help they needed [3]. Ury et al.'s study of multiple courses in a CS program suggests that these challenges may be most severe in introductory courses, as they found no performance differences between online and in-person delivery for higher-level courses [22]. These studies motivate attending to this issue in the present work.

Prior experiences may affect student attitudes towards online learning. Daniels and Feather found that experience with online learning positively affected students' perceptions about its effectiveness [7]. Platt et al. found similar results [19]. Smart and Cappel found that undergraduates who had to take a required course online perceived it more negatively than those who took it as an elective [20]. Such perceptions may affect the online learning experience itself, as Dovbenko et al. found that students who had more negative preconceptions about online learning tended to have a more negative experience in the course [9]. These studies suggest that emergency online learning could have negatively impacted our students' preconceptions as well as their experience.

\section{APPROACH}

Our goal was to understand how students in early CS courses experienced the spring 2020 shift in their global life and educational experience. Our investigation was guided by two questions:

(1) How do students' educational experiences in spring 2020 compare to a typical quarter, in terms of time spent on studies, course success rates, and barriers to learning?

(2) How do students' affective and social experiences in spring 2020 compare to a typical quarter in terms of stress levels, challenge, and connection with peers?

Due to the chaotic and emergent nature of spring 2020, a controlled or even quasi-controlled study that can be replicated was out of the question; our goal was not to determine causal or even correlational relationships between changes in spring 2020 and students' experiences. Instead, we looked for holistic trends from spring 2020 that would indicate how the educational system responded. 
Table 1: Participant numbers in each course

\begin{tabular}{r|c|c|c}
\hline Course Name & Fall $N$ & Winter $N$ & Spring $N$ \\
\hline CS1(Acc) & 443 & 322 & 202 \\
CS1a & 562 & 305 & 270 \\
CS1b & - & 416 & 191 \\
CS2 & 289 & 183 & 781 \\
CS3 & 438 & 241 & 365 \\
CS4 & - & 334 & 566 \\
\hline
\end{tabular}

\subsection{University Context}

UCSD is a large US research university with a 3 quarter system (fall, winter, spring). We examined data from six undergraduate CS courses in all 3 quarters of the 2019-2020 academic year, except for CS1b and CS4, which only have data for winter and spring. CS1(Acc) and CS1a/CS1b are equivalent streams that both teach introductory Object-Oriented Programming in Python and Java. CS1a and CS1b offer the material across two quarters while CS1(Acc) lasts one quarter. CS2 teaches basic data structures in Java; CS3 focuses on system programming with assembly language and C; and CS4 introduces advanced data structures in $\mathrm{C}++$.

COVID-19 mainly affected spring quarter, which runs from early April through mid-June. Fall quarter (October through December) was unaffected, while winter quarter (January through mid-March) was unaffected until final exam week, when some finals were modified or canceled. Spring was conducted completely remotely, with modifications made at both the course and the institutional level. At the institutional level, students were given the option to take courses pass/no-pass where a letter grade is typically required. The deadlines for dropping and withdrawing from courses were extended by one week each. At the course level, instructors made their lectures and all other course material asynchronously available online. Office hours and tutor support were conducted live over Zoom. Most instructors slightly reduced the overall course workload to allow more time for students to adjust to the remote format before the first deadline for graded work. Most midterms and finals were modified to be untimed and open-book/open-notes. Their weight on a student's final grade was also reduced, replaced by multiple lower-stakes assessments such as quizzes.

\subsection{Data Collection and Analysis}

We collected data through weekly or bi-weekly surveys in each course, which students submitted for a small amount of course credit. The survey asked students about their experiences and feelings across a range of areas, both inside and outside the class. In this study we focus on the following questions:

(1) In the last week, approximately how many hours did you spend outside of class time working on work for this course?

(2) How challenging was the work for this class this week?

(3) At this time, approximately how many other students in this course would you be comfortable reaching out to study with?

(4) Reflecting on the last week, how stressed have you been overall?

(5) In the past week to what degree did each of the following interfere with your ability to learn and complete the work for this course? [Requirements for other classes, Illness, Family obligations, Work obligations, Social/personal life issues]
Questions (1) and (3) were numeric open-response, while for questions (2), (4), and (5) students responded on a 5-point scale, where 1 was labeled "Not at all" and 5 was labeled "Extremely/Significantly."

In addition to survey data, we obtained students' final grades, race/ethnicity, gender, transfer status (i.e., whether or not they transferred to UCSD from another college), and first-generation college student status. We included only students who were enrolled in each course at the start of week 3 in order to exclude students who were just trying out the course. Per our approved IRB protocol, our data set includes data only from students who were at least 18 years old and who did not opt out of the study. The numbers of participants from each course in each quarter are given in Table 1.

Overall, 65\% of all assigned surveys were completed in each of fall and winter, while $76 \%$ of all assigned surveys were completed in spring. Only $3 \%, 2 \%$, and $3 \%$ of the students included in Table 1 in fall, winter, and spring, respectively, did not return any surveys at all. To account for the fact that some students answered more surveys than others, we computed means by first taking each individual student's mean response to the relevant question across all of the surveys that student completed. Then we took the average of the these means. Although using means is controversial when analyzing rating data, we deemed it appropriate for two reasons. First, students responded on a numeric scale (1-5), where the differences between levels was explicit and uniform. Second, we compared our mean-based analysis with a non-parametric median-based analysis for the rating data and found that the statistical similarities and differences were qualitatively the same, and displaying means made the data much easier to interpret visually.

We visualize means with error bars representing standard error. When comparing means, we tested for any statistically significant differences between fall, winter, and spring using ANOVA. In cases where we were comparing proportions, such as fail rates, we used a Chi-Squared test to test for significant differences between fall, winter, and spring. We used $p<0.01$ as our threshold for significance, indicated with $\mathrm{a}^{*}$ in our graphs. Before our analysis of the data from survey questions (1) and (3), we removed outliers using the Interquartile Range (IQR) rule, which states points that fell more than $1.5 \mathrm{IQR}$ above the third quartile are removed. ${ }^{1}$

\section{RESULTS}

\subsection{Educational Experiences}

To examine students' educational experience in spring compared to fall and winter, we compared average hours per week spent in each course, drop rates and fail rates, and external factors that might have interfered with students' learning.

Figure 1 shows the average number of hours per week students reported spending in each course from each quarter. Although there is some variation by course, the values in spring quarter did not increase. Post hoc tests using holm error correction reveal that in CS2 and CS4, students reported significantly fewer hours in spring than in fall and winter. In other courses, hours in spring are similar to fall and/or winter. ${ }^{2}$

Next we examined the rates at which students dropped the course before the first drop deadline (Figure 2). Note that the drop rate

\footnotetext{
${ }^{1}$ No points fell more than 1.5IQR below the first quartile.

${ }^{2}$ In CS1(Acc) and CS1a although a main effect was found across quarters, post-hoc tests did not reveal a statistically significant change in spring compared to fall or winter.
} 


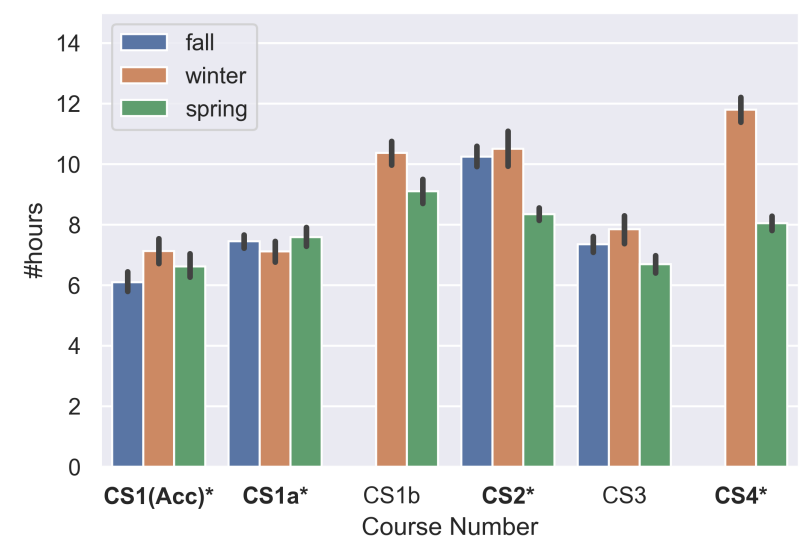

Figure 1: Average hours per course $\left({ }^{*}\right.$ indicates $\left.p<0.01\right)$

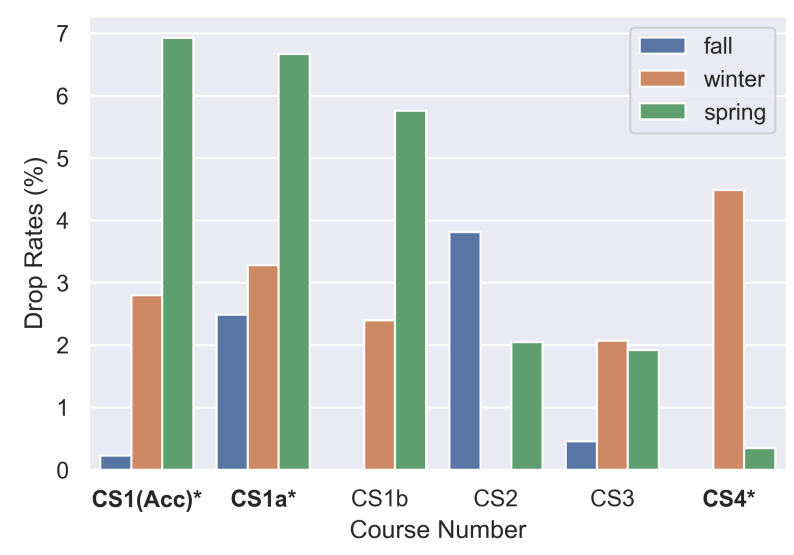

Figure 2: Drop rates $\left({ }^{*}\right.$ indicates $\left.p<0.01\right)$.

for CS2 in winter is 0. Drop rates in CS2, CS3, and CS4 are similar or lower in spring compared to fall and winter. However, for the introductory programming courses (CS1(Acc), CS1a, and CS1b), there is a notable increase in drop rates in the spring quarter, which is statistically significant in CS1Acc and CS1a. This trend may be related to the fact that these courses comprise mainly non-CS majors in spring, who may be more likely to drop a class that is not required for their major. Unfortunately, we do not have the data to compare drop rates in spring 2020 to those in spring 2019.

We also examined the fail rates (defined as the percentage of students who received a grade of a 'D', an 'F', or a 'No-Pass' in the course), which are shown in Figure 3. In this case, we were able to compare fail rates in spring 2020 not only to fall 2019 and winter 2020 (subfigure (b)), but also to rates across the previous (2018-2019) academic year (subfigure (a)). Here we see that compared to fall 2019 and winter 2020, fail rates in spring 2020 are similar or lower for most classes. The one exception is CS1(Acc), but compared to 2018-2019, fail rates in spring 2020 are similar to the fail rates in spring 2019. Indeed, in most courses fail rates overall were lower in spring 2020 compared to the previous year.

Finally, we examined several factors external to the course itself, which might have interfered with students' learning (Figure 4).

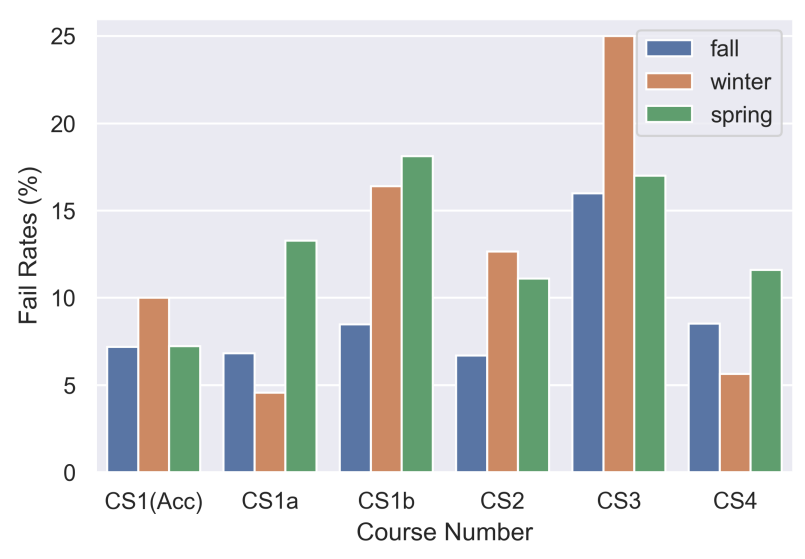

(a) 2018-2019 academic year

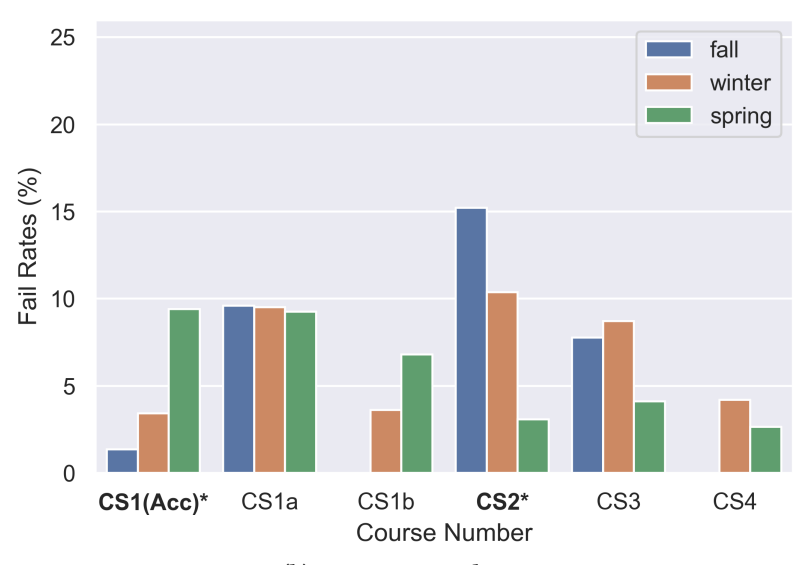

(b) 2019-2020 academic year

Figure 3: Fail rates in 2018-2019 and 2019-2020 academic years $\left({ }^{*}\right.$ indicates $p<0.01$; significance was tested per course between quarters in a single year, not between years)

When we analyzed each factor by course, we found little difference between courses, so Figure 4 shows the impact of the barriers aggregated across all classes in each quarter. Rates of interference in the spring quarter are similar to the winter and fall, with two exceptions: family obligations interfered more in the spring, while illness interfered less. This result is not surprising given that many students were stuck at home.

\subsection{Affective and social experiences}

Next, we examined how student stress, perceptions of challenge, and comfort with peers might have changed across quarters. Figure 5 provides the average perceived stress level of students by quarter and course. Although the differences are significant in many cases, there is no clear trend. CS1a saw an increase from the fall to winter and spring, but most other courses remain level or decline from the fall. Moreover, the changes are small.

Next, we looked at how challenging students felt their courses were in spring compared to fall and winter (Figure 6). Our results show that, if anything, students perceived their courses as less 


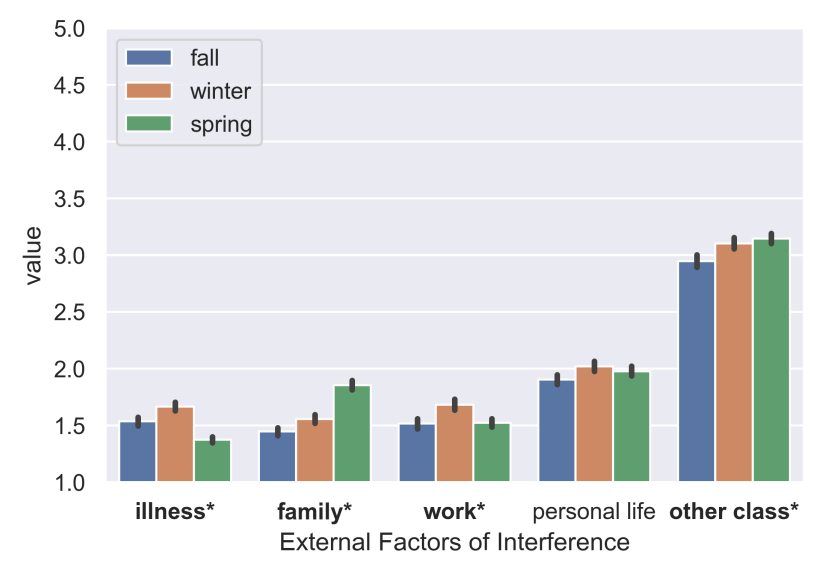

Figure 4: Average reported interference by external factors (1=not at all, $5=$ Significantly; ${ }^{*}$ indicates $\left.p<0.01\right)$

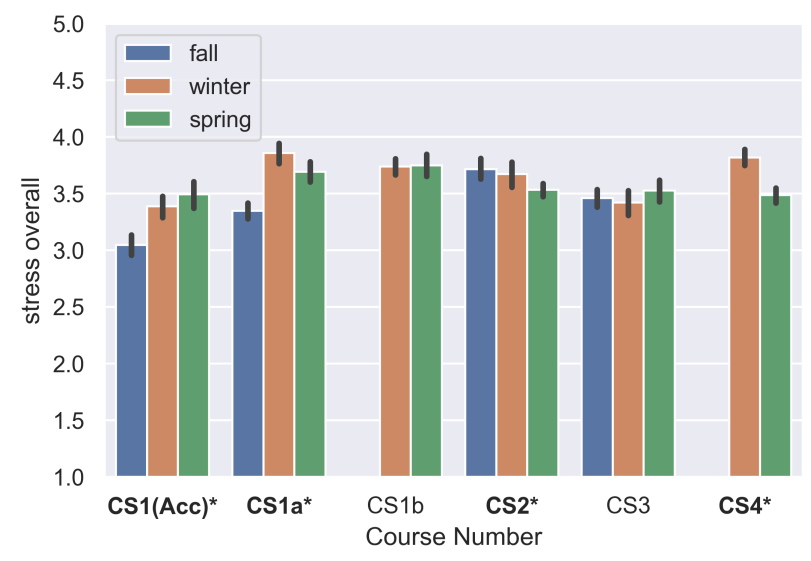

Figure 5: Average overall stress $\left({ }^{*}\right.$ indicates $p<0.01$;)

challenging in the spring, despite the fact that they had to learn new technologies and new interaction patterns.

Finally, we examined students' connection to their peers in spring compared to fall and winter (Figure 7) Here there is a clear and concerning trend. In all courses except CS3, we see a significant drop in the number of peers students feel comfortable reaching out to after the transition online. For the later courses the drop is smaller, as students in these courses likely already have friends in their classes and are more likely to be majors. They may have relied on their existing social networks. Introductory programming students are likely to have no such network to leverage.

\subsection{Demographic Differences}

We hypothesized that students from some demographic groups might be more affected by the switch to remote learning, as has been documented by others [1]. We examined differences in all of the factors we studied by gender, race, transfer status, and first generation college student status. We found notable differences between the experiences of students from different demographic groups within each quarter we studied. For example, Black, Latinx, Native American, and Pacific Islander (BLNPI) students reported having fewer peers they are comfortable studying with than White

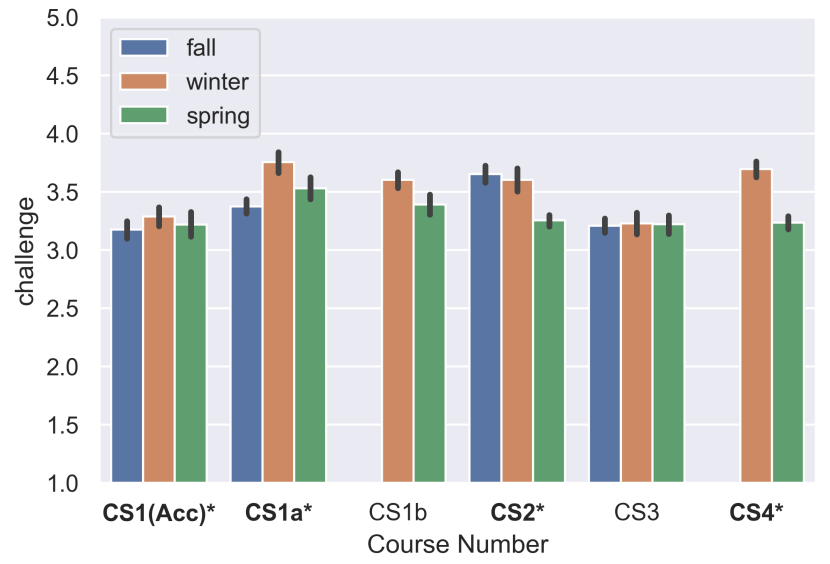

Figure 6: Average perceived challenge $\left({ }^{*}\right.$ indicates $\left.p<0.01\right)$

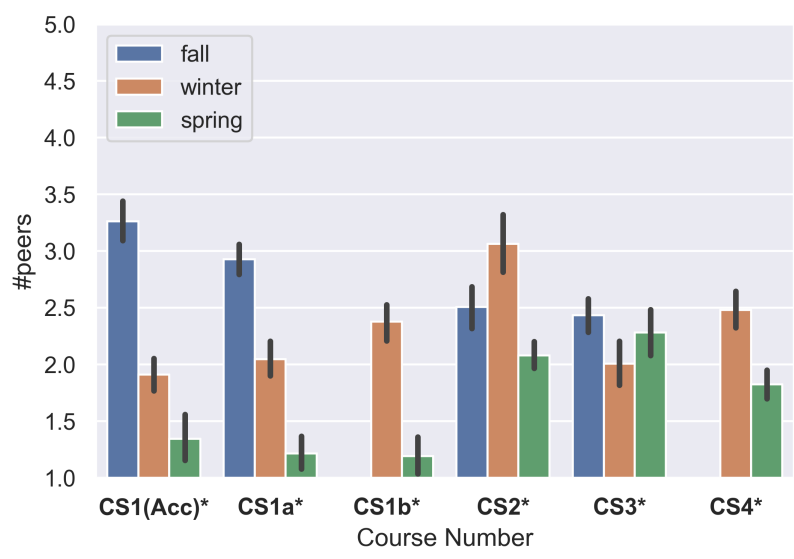

Figure 7: Average \# peers comfortable reaching out to ( ${ }^{*}$ indicates $\left.p<0.01\right)$

Table 2: Percent of surveys returned, by demographic

\begin{tabular}{r|cc|cc|cc}
\hline Term & BLNPI & WA & women & men & transfer & 1 st year \\
\hline Fall & $59 \%$ & $66 \%$ & $68 \%$ & $64 \%$ & $56 \%$ & $67 \%$ \\
Winter & $57 \%$ & $66 \%$ & $66 \%$ & $64 \%$ & $57 \%$ & $67 \%$ \\
Spring & $69 \%$ & $77 \%$ & $77 \%$ & $75 \%$ & $71 \%$ & $77 \%$ \\
\hline
\end{tabular}

and Asian (WA) students. This trend is the same for women vs. men and transfer students vs. first-year (non-transfer) students. However, these differences persisted across all three quarters we studied, and surprisingly, differences were not apparently any larger or smaller in spring than they were in previous quarters.

To verify that the lack of difference in spring was not due to disproportionately missing data (perhaps due to increased struggle), we examined response rates by demographics in each quarter (Table 2). Again, we found differences within each quarter: BLNPI students returned fewer surveys than WA students, women returned slightly more surveys than men, and transfer students returned fewer surveys than first-year students. However, these differences are not notably different in spring compared to winter and fall. 


\section{DISCUSSION}

Our findings indicate that in many ways the educational system at UCSD adapted well to the stresses of spring 2020 from the students' perspective. Although the context does not allow us to directly assess the impact that any particular policy, pedagogical, or structural change had on students' experiences, in this section we discuss aspects of the adaptation that, from our perspective as part of the UCSD CS department, were important contributors to the mostly successful adaptation of the UCSD CS educational system. Finally, we discuss the ways in which the system failed to adapt successfully, and we make suggestions for ways to address these shortcomings.

First, both UCSD and our CS department set an explicit goal during spring quarter of reducing stress among students, in large part by focusing on relieving the stress students feel about grades. The decision to allow students to take courses pass/no-pass without harming progress to their degree alleviated the constant stress that grades can bring. The decision by many faculty to allow "no-fault finals" (where their final exam would count only if it helped their grade) took away some of the pressure of final exam week. The division of few high-stakes assessments into many lower-stakes assessments meant that a stumble would not be catastrophic. These adaptations together seemed to flatten the stress curve. Whereas in previous quarters students' stress would start at a moderate level and then rise sharply around midterms, only to ultimately peak during finals week, in spring we saw stress levels stay lower and much more constant.

A second factor that we believe was central to the overall success of the adaption was the flexibility afforded to students to learn on their own time in their own way. In spring 2020, UCSD required that all assessments and course materials including lectures, quizzes, and exams be available to students at times outside of the scheduled course time, e.g., by recording and posting lectures and by offering asynchronous or makeup exams and quizzes. This increased flexibility gave students agency in their learning, and removed some of the structural barriers that might have interfered with students' learning in previous quarters. Although this level of flexibility did require more instructional resources, it could be carried over into non-pandemic quarters to help improve the student experience.

Third, redesigning courses for remote learning often inspired faculty to make improvements to their pedagogy. For example, some faculty switched from using a straight lecture approach to incorporating pedagogical tools such as interactive textbooks. Others structured their classes around short ( $<5$ minute) pre-recorded video segments which faculty would watch with their students and intersperse with discussion or student question-driven demos of coding concepts. These more up-to-date pedagogical approaches certainly benefited students, and can continue into future quarters.

On the other hand, there were ways in which the system did not provide the needed support to students. In particular, students had fewer peer-to-peer relationships in their courses in the spring, particularly in the early computing courses. Social support is critical in introductory computing courses, and in online courses more generally. Kuo found that in looking at the importance of satisfaction in online courses of graduates and undergraduates, students' satisfaction was impacted by their interaction with each other [13]. Many faculty teaching these courses at UCSD have now focused more of their attention on techniques to foster peer-to-peer relationships in a remote environment. Studying the effects of these efforts is an important avenue of future work.

Finally, we note that although the average struggle and stress faced by students in the spring was generally not higher than in the fall and winter, this does not mean that students did not struggle in the spring. There were certainly some students for whom the accommodations made by the department and the university were insufficient. More targeted, qualitative research is critical to understanding the experiences of these students.

\section{LIMITATIONS AND RISKS TO VALIDITY}

Survey-based research always faces some risks. Self-reporting may be inaccurate and responses may be biased by mood. Although our overall survey response rates were relatively high, they were not uniform across all students. Section 4.3 showed differences in response rates by demographic group. We also found that response rates for lower performing students (those who earned C's, D's, and F's) were significantly lower than higher performing students. The relatively consistent difference in response rates between high and low performers across all three quarters helps mitigate this risk. Yet, the missing data from lower performing, BLNPI, and transfer students hides information about their struggles in all three quarters. We believe this issue is not unique to our study (though it is not usually analyzed or reported), and that finding ways to raise the response rate from these students is important.

Second, we do not have any way to measure what students actually learned in spring compared to fall and winter. We did not analyze relative grades (beyond fail rates) between fall, winter, and spring, because we had reason to believe from talking to the instructors of these courses that the grades would not be comparable.

Finally, it was impossible to design an investigation that would isolate the relationship between specific educational changes and students' experiences. That was never our goal-too many things changed all at once in a chaotic fashion. Although we have given our perspective on what factors we believe contributed to the system to adapting well, or failing to adapt, we cannot be sure what influence these factors actually had.

\section{CONCLUSION}

We conducted a multi-course, full-year, data-driven exploratory study in an attempt to understand how students were affected by remote learning/COVID-19. We found that students' educational experience in their CS classes was impacted, but not in all of the ways we expected. Students had less interaction with peers, but also experienced lower stress and spent the same or less time on their courses. Our work shows that it is possible for a complex sociotechnical system like a research university to adapt to give students quality learning experience, and we believe these adaptations can be applied to improve students' learning experiences in both exceptional and more normal times.

\section{ACKNOWLEDGMENTS}

We thank the instructors and students in the classes included in this study. This material is based upon work supported by the National Science Foundation Graduate Research Fellowship Program under Grant No. DGE-1650112 and NSF Award \#1712508. 


\section{REFERENCES}

[1] Greta Anderson. More pandemic consequences for underrepresented students, 9 2020. URL https://www.insidehighered.com/news/2020/09/16/low-income-andstudents- color-greatest-need-pandemic-relief.

[2] Julio César Bahamón and Audrey Rorrer. Improving student learning outcomes in online courses: An investigation into the effects of multiple teaching modalities. In Proceedings of the 51st ACM Technical Symposium on Computer Science Education, SIGCSE '20, page 1179-1185, New York, NY, USA, 2020. Association for Computing Machinery. ISBN 9781450367936. doi: 10.1145/3328778.3366880. URL https://doi.org/10.1145/3328778.3366880.

[3] Klara Benda, Amy Bruckman, and Mark Guzdial. When life and learning do not fit: Challenges of workload and communication in introductory computer science online. ACM Trans. Comput. Educ., 12(4), November 2012. doi: 10.1145/ 2382564.2382567. URL https://doi.org/10.1145/2382564.2382567.

[4] Betsy Bizot, Ran Libeskind-Hadas, Susanne Hambrusch, Jim Kurose, Lori Pollock, and Nancy Amato. Results of a Summer 2020 Survey of Computer Science Faculty: The Transition to Online Teaching last Spring and Planning for the Fall Technical report, Computing Research Association, 072020.

[5] Jennifer Campbell, Diane Horton, and Michelle Craig. Factors for success in online cs1. In Proceedings of the 2016 ACM Conference on Innovation and Technology in Computer Science Education, ITiCSE '16, page 320-325, New York, NY, USA, 2016. Association for Computing Machinery. ISBN 9781450342315. doi: 10.1145/ 2899415.2899457. URL https://doi.org/10.1145/2899415.2899457.

[6] Tom Crick, Cathryn Knight, Richard Watermeyer, and Janet Goodall. The impact of covid-19 and "emergency remote teaching" on the uk computer science education community. In United Kingdom \& Ireland Computing Education Research conference., pages 31-37, 2020.

[7] Catharina Daniels and Susan R Feather. Student perceptions of online learning: A comparison of two different populations. In Proceedings of the Conference on Information Systems Applied Research, USA. Citeseer, 2002.

[8] Stephanie Dingwall. Lessons learned from active engagement in a largeenrollment introductory biochemistry course during a remote quarter. Fournal of Chemical Education, 0(0):null, 0. doi: 10.1021/acs.jchemed.0c00810. URL https://doi.org/10.1021/acs.jchemed.0c00810.

[9] Svitlana Dovbenko, Ruslana G. Naid, Victor M. Beschastnyy, Halyna V. Bezverkhnia, and Viktoriia V. Tsybulska. Problem of resistance to the introduction of distance learning models of training in the vocational training of educators. International fournal of Learning, Teaching and Educational Research, 22(2):1-12, 02 2020. URL https://doi.org/10.26803/ijlter.19.2.1.

[10] Patricia Fidalgo, Joan Thormann, Oleksandr Kulyk, and José Lencastre. Students perceptions on distance education: A multinational study. International fournal of Educational Technology in Higher Education, 17, 12 2020. doi: 10.1186/s41239020-00194-2.

[11] Rostislav Fojtík. Problems of distance education. International fournal of Information and Communication Technologies in Education, 7(1):14 - 23, 2018. doi: https://doi.org/10.2478/ijicte-2018-0002. URL https://content.sciendo.com/view/ journals/ijicte/7/1/article-p14.xml.

[12] Maureen Hannay and Tracy Newvine. Perceptions of distance learning: A comparison of online and traditional learning. Fournal of Online Learning and Teaching, February 2006. URL https://jolt.merlot.org/05011.htm.

[13] Yu-Chun Kuo, Andrew E. Walker, Kerstin E.E. Schroder, and Brian R. Belland. Interaction, internet self-efficacy, and self-regulated learning as predictors of student satisfaction in online education courses. The Internet and Higher Education, 20:35 - 50, 2014. ISSN 1096-7516. doi: https://doi.org/10.1016/j.iheduc.2013.10.001. URL http://www.sciencedirect.com/science/article/pii/S1096751613000456.

[14] Doug Lederman. How college students viewed this spring's remote learning, 5 2020. URL https://www.insidehighered.com/digital-learning/article/2020/05/20/ student-view-springs-shift-remote-learning.

[15] S. Lei and R. Gupta. College distance education courses: Evaluating benefits and costs from institutional, faculty and students' p2erspectives. Education 3-13, 130: 616-631, 2010

[16] Merry McDonald, Brian Dorn, and Gary McDonald. A statistical analysis of student performance in online computer science courses. In Proceedings of the 35th SIGCSE Technical Symposium on Computer Science Education, SIGCSE '04, page 71-74, New York, NY, USA, 2004. Association for Computing Machinery. ISBN 1581137982. doi: 10.1145/971300.971327. URL https://doi.org/10.1145/ 971300.971327.

[17] Catherine Mooney and Brett A. Becker. Investigating the impact of the covid19 pandemic on computing students' sense of belonging. In Proceedings of the 52nd ACM Technical Symposium on Computer Science Education, SIGCSE '21, page 612-618, New York, NY, USA, 2021. Association for Computing Machinery. ISBN 9781450380621. doi: 10.1145/3408877.3432407. URL https://doi.org/10.1145/ 3408877.3432407

[18] Jasmine Paul and Felicia Jefferson. A comparative analysis of student performance in an online vs. face-to-face environmental science course from 2009 to 2016. Frontiers in Computer Science, 1:7, 2019. ISSN 2624-9898. doi: 10.3389/fcomp.2019. 00007. URL https://www.frontiersin.org/article/10.3389/fcomp.2019.00007.

[19] Carrie Anne Platt, Amber Raile, and Nan Yu. Virtually the same? student perceptions of the equivalence of online classes vs. face-to-face classes. Fournal of Online Learning and Teaching, 10:489-494, 012014.

[20] Karl Smart and James Cappel. Students' perceptions of online learning: A comparative study. FITE, 5:201-219, 06 2006. doi: 10.28945/243.

[21] Heather Thiry and Sarah T. Hug. Sustaining student engagement and equity in computing departments during the covid-19 pandemic. In Proceedings of the 52nd ACM Technical Symposium on Computer Science Education, SIGCSE '21, page 987-993, New York, NY, USA, 2021. Association for Computing Machinery. ISBN 9781450380621. doi: 10.1145/3408877.3432381. URL https://doi.org/10.1145/ 3408877.3432381.

[22] Gary Ury, Merry McDonald, Gary McDonald, and Brian Dorn. Student performance online vs onground: A statistical analysis of is courses. Director, page 07, 2006. 